\title{
Characteristics of water-based drilling mud containing Gilsonite with Boehmite nanoparticles
}

\author{
Pantea PAYDAR ${ }^{1}$, Mojtaba AHMADI ${ }^{2}$ \\ ${ }^{1}$ Chemical engineering student of Razi University in Kermanshah \\ ${ }^{2}$ Assistant Professor of Razi University in Kermanshah
}

\begin{abstract}
Increase the drilling efficiency of the drilling, such as nanoparticles and polymers with additives, is one of the most efficient in the drilling operation. In this project, the impact of boehmite nanoparticles and polymer combination of xanthan on the drilling mud has been studied. Rheological properties of drilling mud (plastic viscosity, yield point and viscosity) boehmite nanoparticles and polymer composition in various concentrations by Rotary Brookfield viscometer model DV-III Ultra are measured. Test results on the rheological properties of muds to the point of the optimal concentration range is equivalent to 0.06 grams boehmite nanoparticles show.
\end{abstract}

Keywords: Boehmite Nanoparticles, Xanthan gum polymer, drilling mud (fluid), rheological properties

\section{Introduction}

Improved drilling fluid properties as an important factor in increasing the efficiency of drilling operations had been the focus of attention. A way to improve the properties of these fluids is to use new additives, such as various polymers and nanoparticles. Although drilling fluids have many advantages for the drilling process, but drilling fluids high-pressure causing onset of these fluids into the penetration formations. This permeability making fluid loss reduction and eventually declining rheological properties control of drilling mud. Therefore during operation by adding different additives into drilling mud for producing suitable mud cake and controlling fluid loss and rheological properties can improvement rheological properties of drilling mud.

\subsection{Nanoparticles of drilling mud}

Nano-base drilling fluid is a fluid that at least has a Nanoparticle by size 1-100 $\mathrm{nm}$. The ultimate goal of using nanoparticles in the drilling mud is to reduce the costs of drilling mud by reducing consumption and improving properties of drilling mud [2]. By adding nanoparticles to drilling mud some fluid properties such as density, viscosity and thermal stability are affected. So improved drilling fluid with nanoparticles has good rheological properties, optimal filtration control, high suspension stability, good lubrication and high anti-pollution power. As result improved drilling fluid causes improve drilling mud technology and meets the needs of drilling operations in complex situations [2].

\subsection{The main applications of drilling muds Nanoparticles include}

\subsubsection{Preventing of flushing drill}

Drilling mud containing nanoparticles because of their ability to form a hydrophobic film on the head of drill and sustainable levels are able to fully prevent of flushing drill and sustainable levels [3]. 


\subsubsection{Removal of toxic gases}

Hydrogen sulfide is highly corrosive, toxic and dangerous gas that can permeate into permeable formations during drilling operation. In order to reduce environmental pollution, protect the health of workers and prevent corrosion of pipelines and drilling equipment the gas must be removed from the mud [3].

\subsubsection{Fluid loss control and stability wells}

Keeping wells sustainability in the drilling operation is very important. But most water-based drilling fluids easily penetrate into penetration shale formations that causing problems such as well instability, destruction of wells, wrinkling and adherence of pipes. The reason is that commonly nanoparticles that used in drilling mud are so large and cannon fill completely nanometer pores shales and permeable formations. Therefore, the use of additives such as nanoparticles can be overcome this problem. To prevent or reduce fluid loss can be used some materials such as gilsonite, polymers, different nanoparticles such as boehmite, bentonite, calcium carbonate, etc [4].

\subsubsection{Confront the challenges of the tanks high temperature and pressure}

Drilling fluid systems in high temperature-high pressure condition have very low heat transfer coefficient. So cooling performance drilling fluids reduced due to the heat dissipation of equipment levels in deep wells. Therefore thermal degradation at high temperatures is one of the major concerns of equipment failure in these conditions. To solve this problem can be used of these additives for increasing nano-fluids thermal conductivity by attention to Surface to volume ratio of nanoparticles [3].

\subsubsection{A variety of nano additives in drilling mud}

Due to the small size of nanoparticles, is preferred to be used them in drilling mud. Because of the friction forces of these nanoparticles is negligible and have lower motor power efficiency. Moreover, from an environmental standpoint, the use of nanoparticles in drilling mud is better than conventional additives . Because nanoparticles at low amounts and low concentrations are added as a percent [3]. In the following a few examples of nano-additives to drilling mud to be expressed.

\subsection{Nano metal oxide}

Nanoparticles of metal oxides are one type of nanoparticles that widely used as drilling mud additives. Nanoparticles to improving the mechanical and rheological properties of drilling mud, preventing of mixing mud and shale, reducing the permeability of the filter cake, reducing fluid loss, maintaining mud properties at High temperature-High pressure, improving the electrical properties of mud, increasing the wellbore stability and also is used as a lubricant.

\subsection{Nano zinc oxide}

Adding zinc oxide nanoparticles in drilling mud causes that during a chemical reaction, all of the hydrogen sulfide gas, which is highly toxic and corrosive gas and have a negative and harmful effects on drilling process, removed of mud. The use of these nanoparticles improved the mechanical and 
rheological properties of drilling mud, reducing the permeability of the filter cake, increasing well bore stability and reducing fluid loss in condition of High pressure-High temperature are.

\subsection{Nano-iron oxide (III)}

The use of nano-iron oxide (III) as add to mud torque and drag forces is reduced. The high-pressure hightemperature conditions also nanoadditives used to reduce fluid loss. Add this nanoparticle to enhance sustainability goals wells, mechanical and rheological properties of drilling mud and filter cake permeability is also reduced.

\subsection{Nano Silica}

Nano silica of the most widely used in the drilling mud. Silica nanoparticles can have different effects on drilling mud such as reducing fluid loss, improving the stability of the well (to reduce formation damage), as well as maintaining high-temperature properties of drilling mud under high pressure.

\subsection{Carbon nanostructure}

Another nano additives that most widely used in drilling mud is carbon nanostructures. These nanostructures applied to improve the heat transfer coefficient, rheological properties and muds sustainability, improve the electrical properties of mud, increase fluid weight, reduce fluid loss, reduce corrosion of drilling equipment and protection of rheological properties of drilling mud at high temperature [5]. In following are two common types of carbon nanostructures is introduced:

\subsection{Graphene}

Graphene is a type of nanostructures that is used in drilling mud for reducing fluid loss, increasing the stability of wells, reducing torque and drag, improving electrical properties and improving dielectric constant of drilling mud, improving the rheological properties of the fluid and increasing the stability of drilling mud $[3,5]$.

\subsection{Carbon nanotubes}

By adding carbon nanotubes to drilling mud meanwhile, reduce fluid loss, can control the weight of the mud. Moreover, can be used of these nanostructures in drilling mud in high-pressure high-temperature condition. Other sufficiency of these nanotubes are including increase the stability of wells, reduce of flushing drill and decrease the torque and drag forces can be mentioned $[3,5]$.

\subsection{Nano-Iron hydroxide}

Iron hydroxide nanoparticles can be used to drilling mud for reducing fluid loss and increasing the stability of the well.

\subsection{Nano Emulsions}

Nano emulsions are used in drilling mud to reducing fluid loss, decreasing formation torque and drag forces [6]. 


\subsection{Nano Polymers}

Different kinds of nano polymers for improving the rheological properties of drilling mud is used in drilling mud. In other words, nano-polymers are one of the most widely nano structures that used in drilling mud. Some of these nano polymers are including poly methyl methacrylate, hydroxyethyl methacrylate and nano-cellulose fibers $[3,6]$.

\subsection{Boehmite nanoparticles}

Boehmite a stable quasi phases of aluminum oxide by simultaneously links of Hydroxide and oxide. Boehmite with hydroxyl functional groups of active and functional nanostructures in the surface. Boehmite powder, is a white powder with a particle size of $10-30 \mathrm{~nm}$. In Figure 1 the molecular structure of boehmite is provided[6].

\subsection{Boehmite nanoparticle applications}

The uses of boehmite nanoparticles can be mentioned are absorbent of chemical materials and heavy metals, preparation of nano-catalysts, paint industry, water treatment and wastewater treatment, cosmetics, ceramics production, polymeric membranes and drug.

In a study at a drilling fluid systems based on surfactant and polymer have been used of nanoparticles to reduce fluid loss and improve the quality of mud cake. The use of nanoparticles reduces fluid loss. Quality of mud cake that created by the combination of nanoparticles and biopolymer is better and thinner than the quality of mud cake that produced by polymer [7]. In another study graphene is used for as filtration control [8]. The graphene sheets cause filtration control by forming a thin layer with a thickness of one $\mathrm{nm}$ on the surface of the wells $[8,9]$.

In the study carbon nanotubes is used at concentrations of less than $3 \mathrm{wt} \%$ with a diameter of 10 to $30 \mathrm{~nm}$ and a length of 0.1To $10 \mathrm{Mm}$, and surface area of 200 to 250 square meters per gram and bulk density among 0.03 to 0.05 Grams per cubic centimeter as Sustainable viscosifier at temperatures up to $325^{\circ}$ [10]. In another study, the effect of using hydrophobic silica and hydrophobic nano-clay on rheology of inverted emulsion been investigated. that both nano additives are effective in stabilizing of emulsions and a combination of both substances would provide the best rheology and emulsion stability[11].
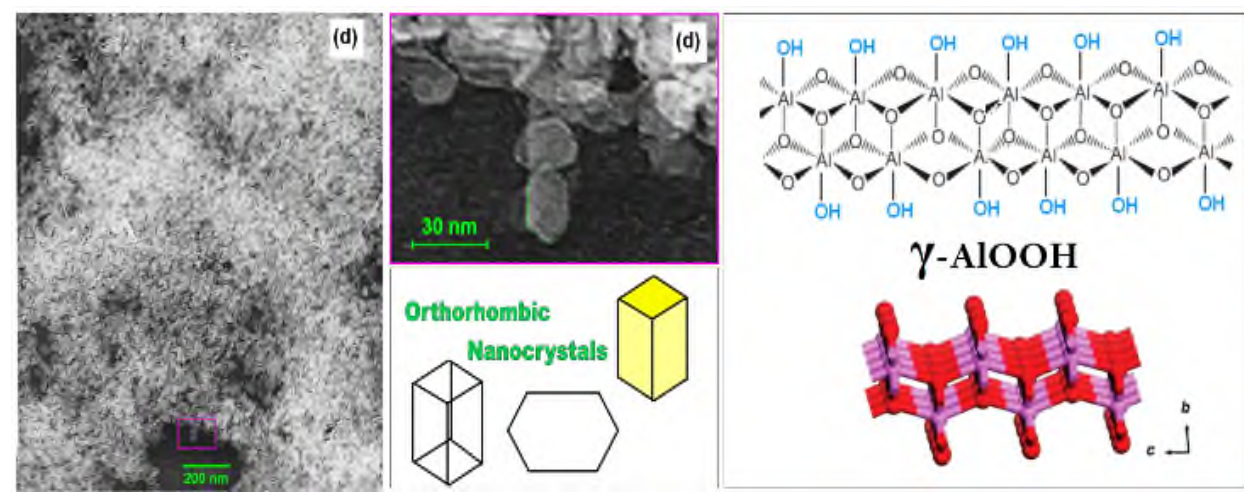

Figure1: Shape and molecular structure of nano-boehmite 
The project aims to study the rheological properties of drilling mud by using bohemite Nano particles to drilling mud.

\section{Materials}

Boehmite, xanthan polymer, gilsonite, bentonite and water. Materials and quantities required for the preparation of six and are represented in Table 1.

\subsection{Systems}

Systems used in the project is including a mixer for mixing materials and Creating a fluid and rotary viscometer Brookfield model (DV-III Ultra) that in order to obtain rheological parameters of drilling mud.

\subsection{The model used in the evaluation of the rheological properties of drilling mud}

Two-parameter Bingham model is a model that is often used to demonstrate the properties of the drilling fluid. This model shows shear stress with increasing shear rate after the necessary initial force to move the fluid.

\section{Laboratory activities}

In this project to investigate the characteristics of water-based mud containing gilsonite with boehmite nanoparticles were used some materials such as boehmite, xanthan gum, gilsonite, bentonite and water. In this project 12 examples were built. To build samples 1 to 6 first $350 \mathrm{ml}$ of water with 4.5 grams of gilsonite was poured into a beaker and stirred with a stirrer for 5 minutes. Then Bentonite was added to the mixture and then the mixture was stirred for 5 minutes. After that xanthan (the amount of which varies in each experiment) was added to the mixture until the mixture was uniformed, was stirred. The entire process was carried out for making 7 to 12 samples and also at the end of boehmite nanoparticles (the amount of which varies in each experiment) was added to mixture. Stirring the mixture with stirring until completely dissolved nanoparticles, continued. After uniform mixing, the mixtures were poured in the sample container. Finally, all samples were analyzed with rotary viscometer Brookfield model ( DV-III Ultra) to study rheological properties of drilling mud. In Table 1 the amount of material needed to produce samples 1 to 6 are provided. In Table (2) the amount of material needed to construct examples 7 to 12 are provided. In table (3) measurement results of rheological properties of drilling mud in the round 40 (rpm) of rotary viscometer for 1 to 6 samples are provided. In Table (4) The results of the measurement of the rheological properties of drilling mud in the round 40 (rpm) of rotary viscometer for 7 to 12 samples are provided. In Figure (2) is shown rotary viscometer. 
Bulletin de la Société Royale des Sciences de Liège, Vol. 86, special issue, 2017, p. 248 - 258

Table 1: Materials and quantities of them that used in samples 1 to 6

\begin{tabular}{|c|c|c|c|c|}
\hline Tests & $\begin{array}{c}\text { Bentonite } \\
(\mathrm{gr})\end{array}$ & $\begin{array}{c}\text { Gilsonite } \\
(\mathrm{gr})\end{array}$ & $\begin{array}{c}\text { Xanthan } \\
(\mathrm{gr})\end{array}$ & $\begin{array}{c}\text { Water } \\
(\mathrm{cc})\end{array}$ \\
\hline 1 & 10 & 4.5 & 0 & 350 \\
\hline 2 & 10 & 4.5 & 0.5 & 350 \\
\hline 3 & 10 & 4.5 & 1 & 350 \\
\hline 4 & 10 & 4.5 & 1.5 & 350 \\
\hline 5 & 10 & 4.5 & 2 & 350 \\
\hline 6 & 10 & 4.5 & 2.5 & 350 \\
\hline
\end{tabular}

Table 2: Materials and quantities of them that used in samples 7 to 12

\begin{tabular}{|c|c|c|c|c|c|}
\hline Tests & $\begin{array}{c}\text { Bentonite } \\
(\mathrm{gr})\end{array}$ & $\begin{array}{c}\text { Gilsonite } \\
(\mathrm{gr})\end{array}$ & $\begin{array}{c}\text { Xanthan } \\
(\mathrm{gr})\end{array}$ & $\begin{array}{c}\text { Boehmite } \\
(\mathrm{gr})\end{array}$ & $\begin{array}{c}\text { Water } \\
(\mathrm{cc})\end{array}$ \\
\hline 7 & 10 & 4.50 & 1 & 0 & 350 \\
\hline 8 & 10 & 4.50 & 0.98 & 0.02 & 350 \\
\hline 9 & 10 & 4.50 & 0.96 & 0.04 & 350 \\
\hline 10 & 10 & 4.50 & 0.94 & 0.06 & 350 \\
\hline 11 & 10 & 4.50 & 0.92 & 0.08 & 350 \\
\hline 12 & 10 & 4.50 & 0.90 & 0.1 & 350 \\
\hline
\end{tabular}

Table 3: The measurement results on the rheological properties of drilling mud in round40 (rpm ) of rotary viscometer for samples 1 to 6

\begin{tabular}{|c|c|c|c|}
\hline Tests & $\begin{array}{c}\text { PV } \\
(\mathrm{cp})\end{array}$ & $\begin{array}{c}\text { YP } \\
\left(\mathrm{D} / \mathrm{cm}^{2}\right)\end{array}$ & $\begin{array}{c}\text { Vis } \\
(\mathrm{cp})\end{array}$ \\
\hline 1 & 4.55 & 4.11 & 5.4 \\
\hline 2 & 18 & 12.4 & 36.5 \\
\hline 3 & 50.04 & 24.50 & 74 \\
\hline 4 & 96.30 & 33 & 122 \\
\hline 5 & 384.5 & 141.7 & 183 \\
\hline 6 & 386.9 & 149.9 & 182 \\
\hline
\end{tabular}


Table 4. The measurement results on the rheological properties of drilling mud in round40 (rpm ) of rotary viscometer for samples 7 to 12

\begin{tabular}{|c|c|c|c|}
\hline Tests & $\begin{array}{c}\text { PV } \\
(\mathrm{cp})\end{array}$ & $\begin{array}{c}\text { YP } \\
\left(\mathrm{D} / \mathrm{cm}^{2}\right)\end{array}$ & $\begin{array}{c}\text { Vis } \\
(\mathrm{cp})\end{array}$ \\
\hline 7 & 50.04 & 24.5 & 74 \\
\hline 8 & 48.20 & 25.20 & 73.24 \\
\hline 9 & 61.60 & 26.60 & 85.33 \\
\hline 10 & 103 & 34.3 & 127.2 \\
\hline 11 & 111 & 35.1 & 134.4 \\
\hline 12 & 72.9 & 29.7 & 98.35 \\
\hline
\end{tabular}

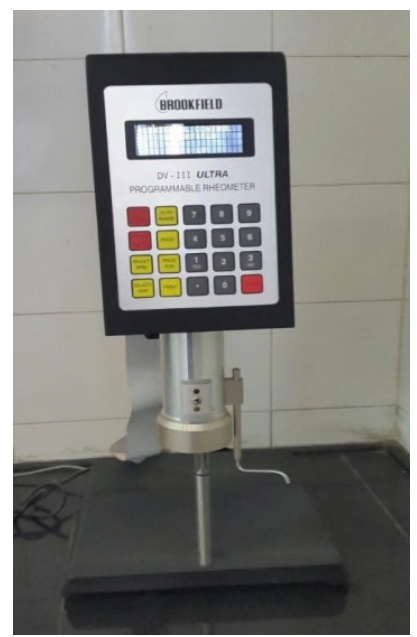

Figure2. Rotary viscometer system used to determine the rheological properties of drilling mud

\section{Results and discussion}

\subsection{The effect of concentration of xanthan polymer (XC) on the plastic viscosity}

Polymers are important additives in drilling fluid. Polymers are used to adjust the rheological properties of drilling mud. In this project by using different concentrations of $\mathrm{XC}$ polymer, the rheological properties of drilling mud was investigated. In Figure 3 the effect of different concentrations of XC on plastic viscosity of drilling fluid is provided. 


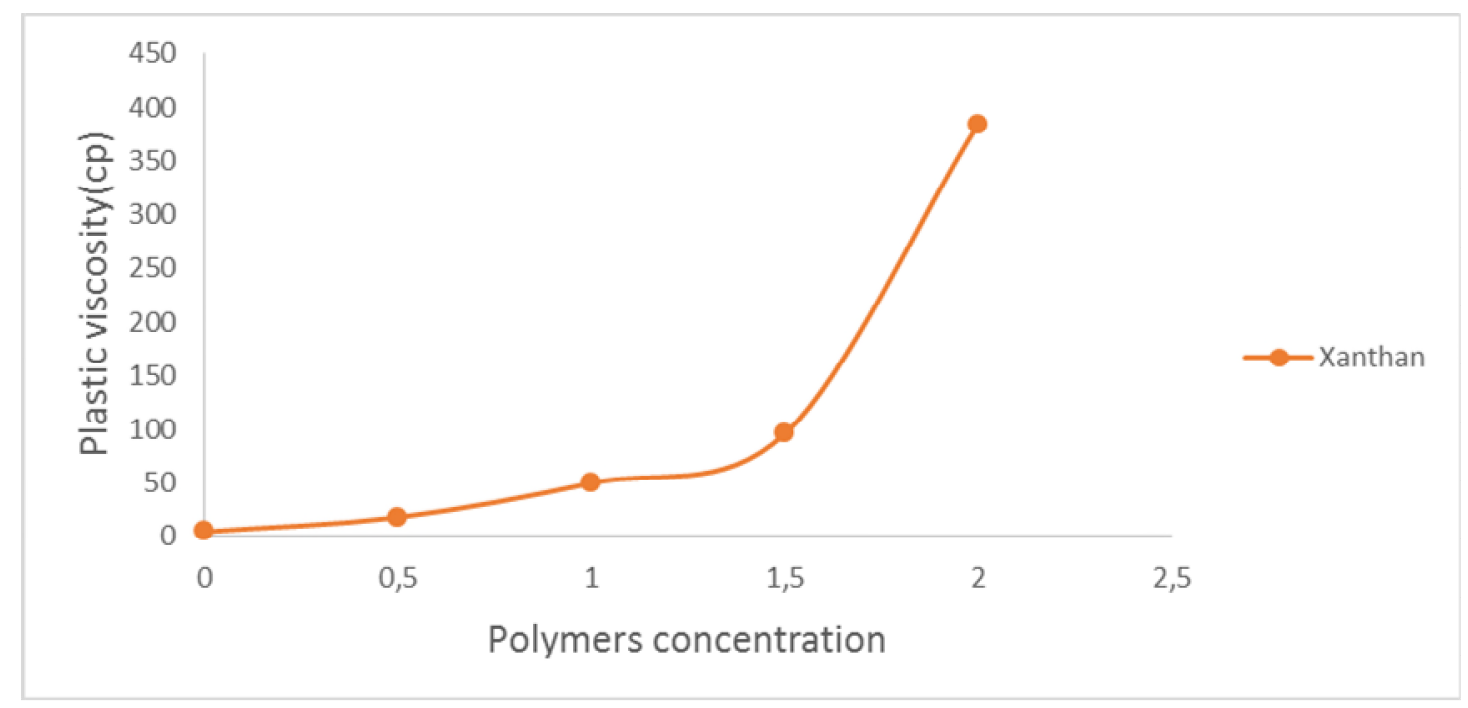

Figure3: The effect of different concentrations of Xanthan on drilling muds plastic viscosity

As in Figure (3) can be seen by increasing the polymer concentration the plastic viscosity increases and this increases is negligible until 1.5 grams of xanthan gum concentration. But after that it has a sharp increase in plastic viscosity. In Figure (4) is shown the effect of different concentrations of XC polymer concentration on yield point of drilling mud. In XC polymer, the concentration range up to a concentration of $5.1 \mathrm{gr}$ yield point indicated increase extremely. In Figure (5) is shown the effect of XC concentration on the fluid. The $\mathrm{XC}$ polymer shows the mild increase in viscosity in the concentration range. Also by increasing concentrations in concentration range viscosity increase is observed.

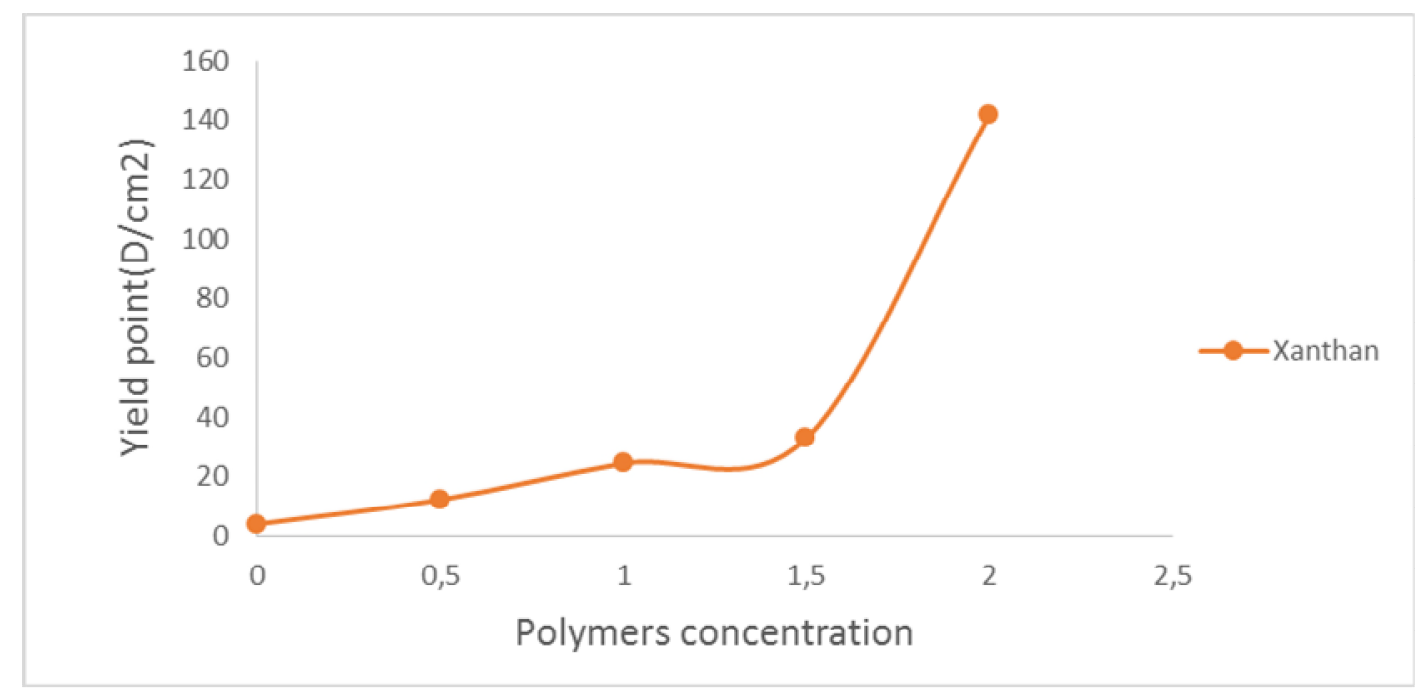

Figure4. The effect of different concentrations of Xanthan on drilling muds yield point 


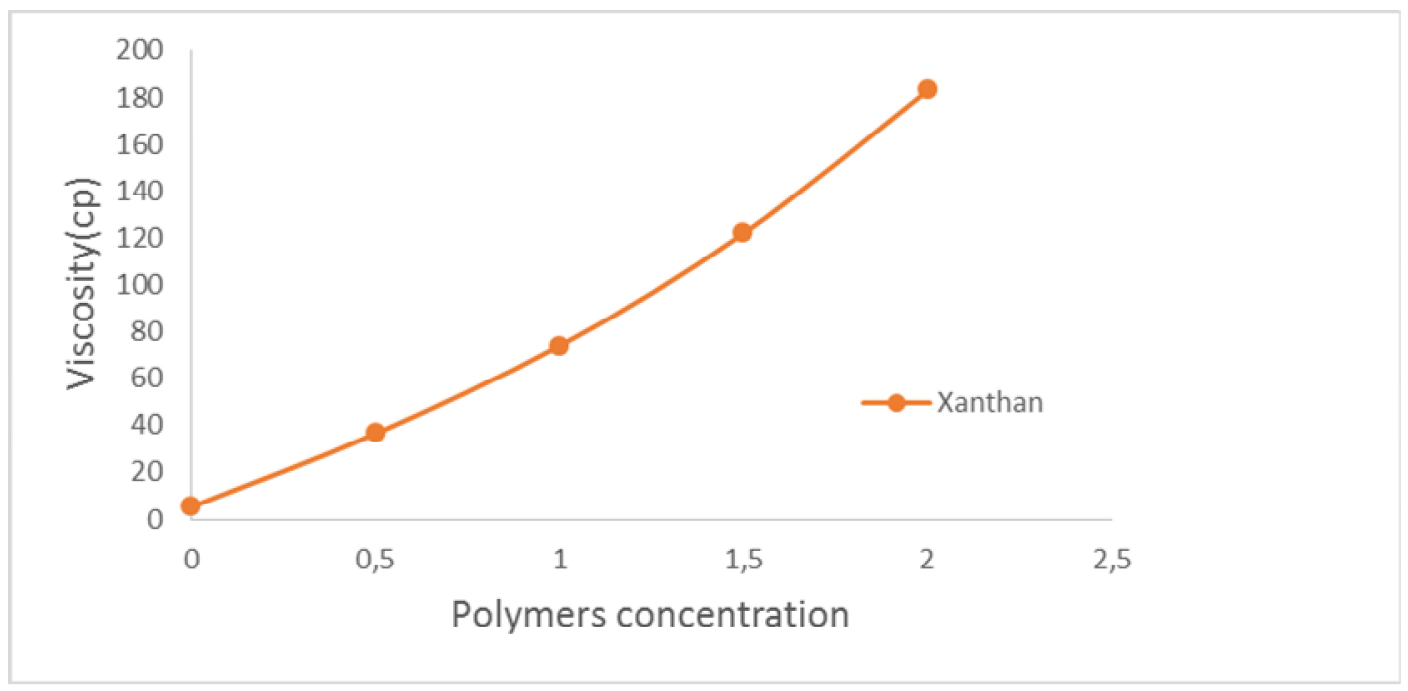

Figure5. The effect of different concentrations of Xanthan on drilling muds viscosity

\subsection{The effect of boehmite nanoparticles on plastic viscosity}

Boehmite nanoparticle is a kind of nanoparticles that is added to drilling mud to improve the rheological properties and reduce the cost of drilling mud. Due to the expensive nature of polymers for using in industrial scale can be used combination of nanoparticles and polymer instead of using only the polymer nanoparticles. In this project is used six different concentrations of nanoparticle and polymer compound in drilling fluid. Using different concentration of nanoparticle and polymer in the certain range of concentration the changes in the rheological properties of drilling mud was investigated. In Figure (6) the effect of different concentrations of nanoparticle and polymer compound in drilling fluid, is provided.

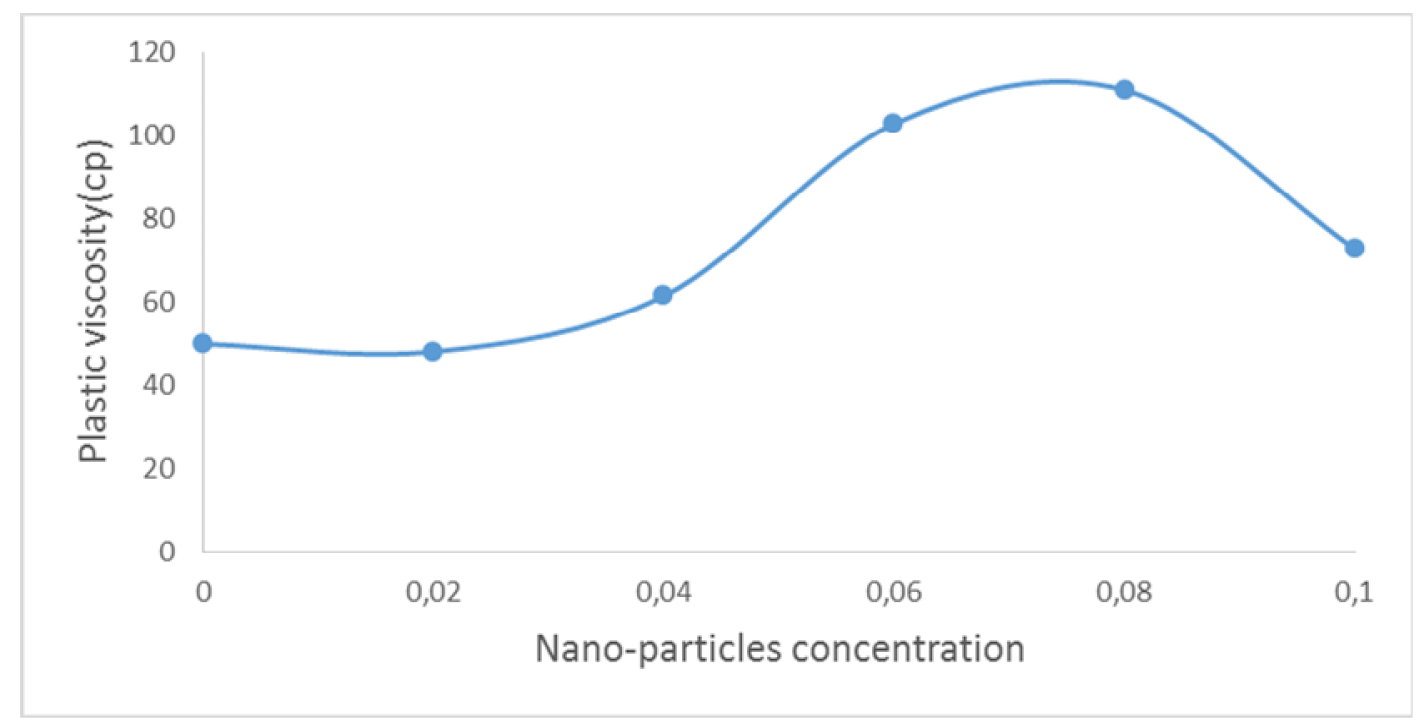

Figure6: The effect of different concentrations of polymer and nano-boehmite on drilling muds plastic viscosity

As can be seen in Figure (6) with increasing concentrations of nanoparticles to the amount of $0.06 \mathrm{~g}$ in the concentration range, the viscosity shows increased dramatically. But then concentration, plastic viscosity is downward and dropped. Also search for yield point and viscosity results are provided alternatively in 
Figure (7) and (8) are provided. In Fig (7) It is seen that with increasing nanoparticle concentration till 0.04 gr, yield point has not significant changed. But after that point until 0.06 gr of nanoparticle concentration in a certain concentration range, increasing the yield point can be seen. And in the concentration range of $0.06 \mathrm{gr}$ to $0.1 \mathrm{gr}$ of nanoparticle concentrations, reducing the yield point can be seen. In Figure (8) can be seen mild increase for viscosity with increasing nanoparticle concentration to $0.04 \mathrm{gr}$. And can be seen significant increase for viscosity till 0.06 gr concentration in the concentration range. And be observed sharp reduction in viscosity after that concentration.

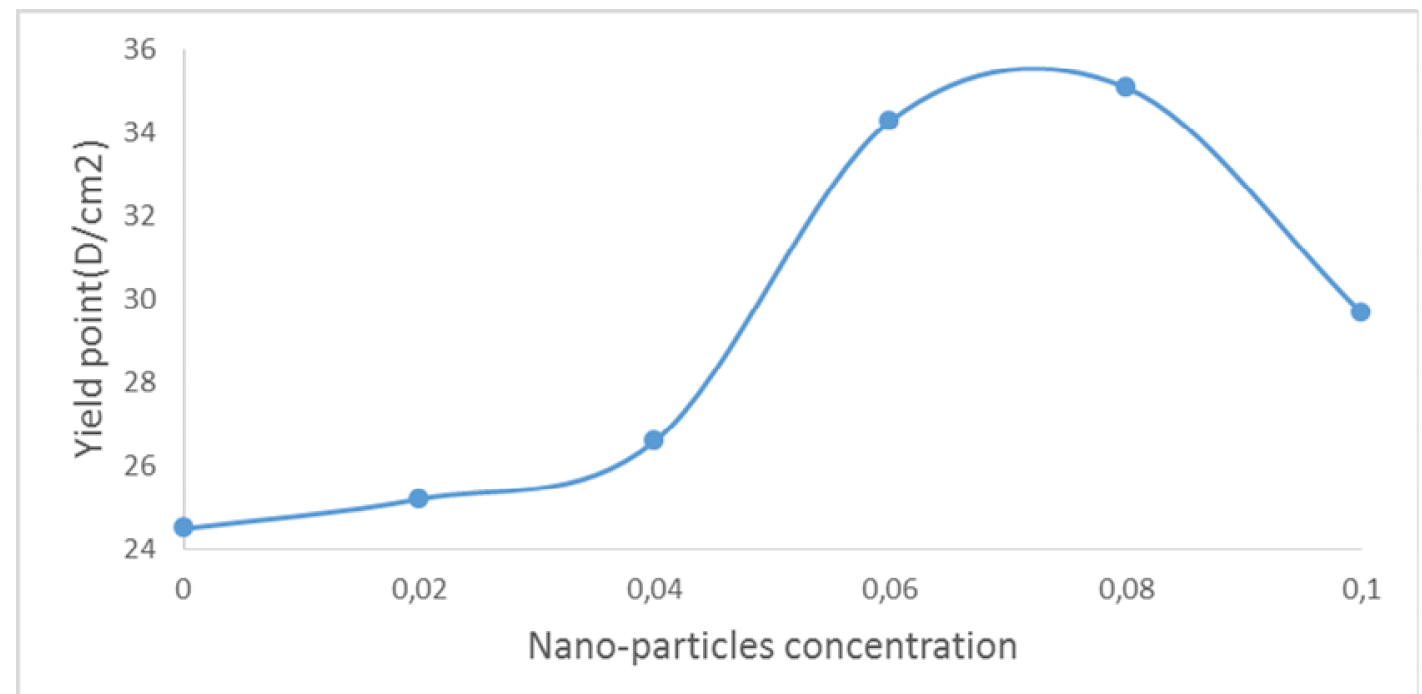

Figure7: The effect of different concentrations of polymer and nano-boehmite on drilling muds yield point

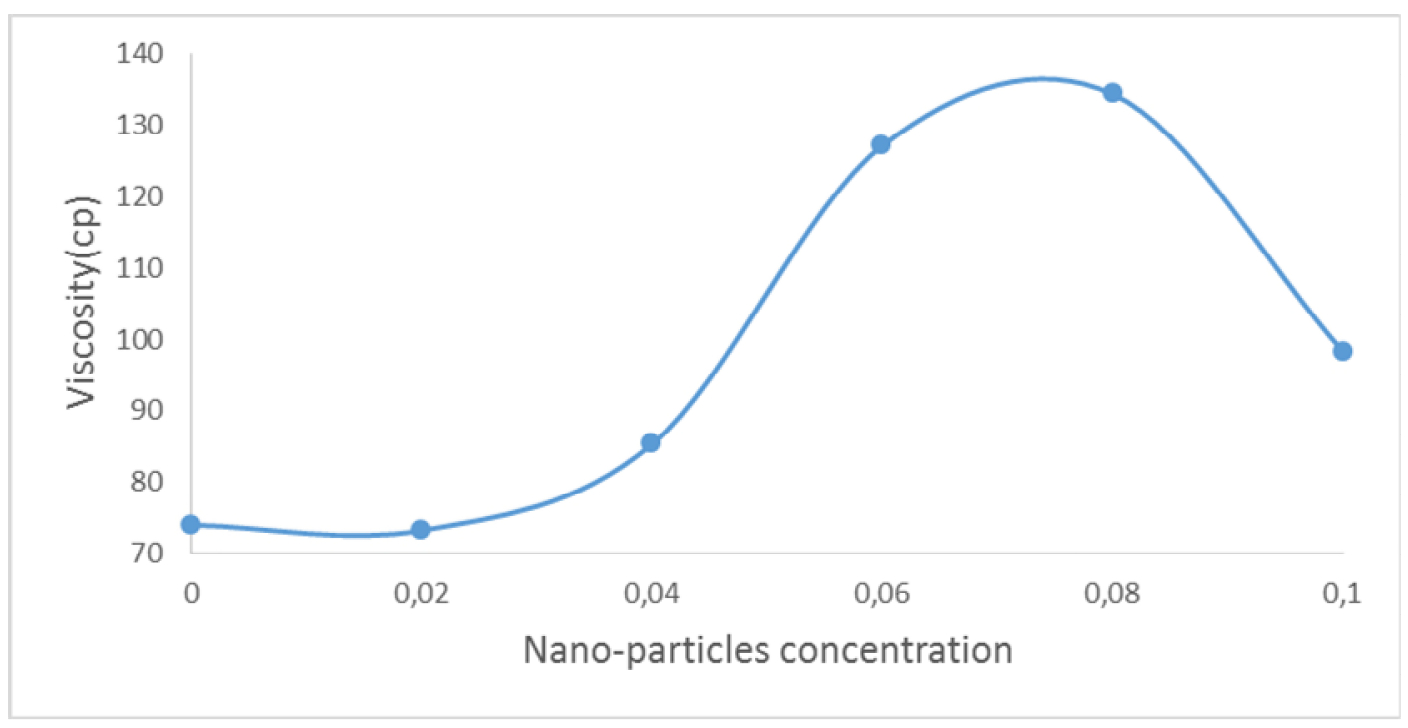

Figure8: The effect of different concentrations of polymer and nano-boehmite on drilling muds viscosity

\section{Conclusion}

By adding XC polymer to drilling mud and using Bingham model of brokfield viscometer model (DV-III Ultra) the rheological properties of drilling mud (plastic viscosity, yield point and viscosity) were measured and the results of the tests showed an increase in plastic viscosity, yield point and viscosity . 
The results of the addition of nano-boehmite to a concentration of $0.06 \mathrm{gr}$ showed the improvement of rheological properties of drilling mud. But with the increasing concentration of more than 0.06 grams boehmite nanoparticle, the nanoparticle has the opposite effect on the rheological properties of drilling mud. This is due to at the higher concentration, nano particles stick to each other and loose their properties and thus reduce the efficiency of the drilling mud and drilling operations. On the other hand the concentration of 0.06 grams of nanoparticles, considered to be the optimum concentration and improve the rheological properties of the mud. In comparison of using XC and combination of XC and nanoboehmite in both of then increase the rheological properties. Actually the use of nano-boehmite in drilling mud reduces drilling costs through reduction of polymer materials consumption and achieve to required optimized and increase drilling mud efficiency Compared to just using polymer drilling mud.

\section{References}

[1] A, Ghaderi., O, Kheirizadeh., "Mud drilling engineering", Ava puplishing,2012.

[2] A.S. Apaleke, A. Al-Majed, M.E. Hossain, Drilling fluid: state of the art and future trend, in: North Africa Technical Conference and Exhibition, SPE, Cairo, Egypt, 2012.

[3] A.I. Diasty, A.M.S. Ragab, Application of nanotechnology in oil \& gas industry: Latest trends worldwide \& future challenges in Egypt, in: North Africa Technical Conference \& Exhibition, SPE Cairo, Egypt, 2013.

[4] L. Long, X. Xianguang, S. Jinsheng, Y. Xubo, L. Yingmin, Vital role of nanomaterials in drilling fluid and reservoir protection applications, in: International Petroleum Conference and Exhibition, SPE, Abu Dhabi, UAE, 2012.

[5]H,Rezaee., M, Javadi., M,Afshaepour," Introduction to produce nano-materials, properties and applications",2013.

[6]a,Nasiri., M, Valizadeh.," Partially hydrolyzed polyacrylamide efficiency in water-based drilling fluids", Journal of Polymer Science and Technology,page3-13,2013.

[7] Jayanth T. Srivatsa, Malgorzata B. Ziaja, Texas Tech University in Lubbock, 2012, “An Experimental Investigation on Use of Nanoparticles as Fluid Loss Additives in a Surfactant - Polymer Based Drilling Fluids", International Petroleum Technology Conference, 14952-MS.

[8] James M. Tour, Howard K. Schmidt, Condell D. Doyle, Dmitry V. Kosynkin, Jay R. Lomeda, 2011, “Graphene Compositions and Drilling Fluids Derived Therefrom”, United States Patent Application US 2011/0144386 A1.

[9] Bergman, Jeffrey, S., 2012, "GRAPHENE-BASED MATERIAL FOR SHALE STABILIZATION AND METHOD OF USE", international publication number wo 2012/048068 A2.

[10] Nicolas Passade-Boupat, Cathy Rey, Mathieu Naegel "DRILLING FLUID CONTAINING CARBON NANOTUBES”, United states patent application publication, Publication number: US

[11] By Sushant Agarwal, Phuoc Tran, Yee Soong, Donald Martello and Rakesh K. Gupta, 2011, "Research Shows Benefits Of Adding Nanoclay, Nanosilica To Oil-Based HP/HT Drilling Fluids", The American Oil \& Gas Reporter. 